\title{
Use of recombinant human bone morphogenetic protein for revision cervical spine fusion in children with Down syndrome: a case series
}

\author{
Lara L. Cohen, MPH, ${ }^{1}$ Brian W. Yang, MD, ${ }^{1}$ Nora P. O'Neill, BA, ${ }^{1}$ Mark R. Proctor, MD, ${ }^{2}$ \\ Michael P. Glotzbecker, MD, ${ }^{1}$ and Daniel J. Hedequist, MD ${ }^{1}$ \\ Departments of ${ }^{1}$ Orthopaedic Surgery and ${ }^{2}$ Neurosurgery, Harvard Medical School/Boston Children's Hospital, \\ Boston, Massachusetts
}

OBJECTIVE Patients with trisomy 21 (Down syndrome; DS) often have atlantoaxial instability (AAI), which, if severe, causes myelopathy and neurological deterioration. Children with DS and AAI who undergo cervical spine fusion have a high rate of nonunion requiring revision surgery. Recombinant human bone morphogenetic protein-2 (rhBMP-2) is a TGF- $\beta$ growth factor that is used to induce bone formation in spine fusion. Although previous studies in the adult population have reported no reduction in pseudarthrosis rates with the use of rhBMP-2, there is a lack of literature in the pediatric DS population. This study describes the use of rhBMP-2 in children with DS and AAI during revision to treat nonunion.

METHODS A retrospective review of a cervical spine fusion database $(n=175)$ was conducted. This database included all cervical spine fusions using modern instrumentation at the authors' institution from 2002 to 2019. Patients with DS who underwent a revision utilizing rhBMP-2 were included in the study. The number of prior fusions, use of rhBMP-2 in fusions, length of stay, halo use, and surgical data were collected. Postoperative complications and length of follow-up were also recorded.

RESULTS Eight patients (75\% female) met the inclusion criteria. The average age at revision with rhBMP-2 was 11 years (range 3-19 years). All patients were diagnosed with nonunion after an initial cervical fusion. All revisions were posterior fusions of C1-2 $(n=2)$ or occiput to cervical $(n=6)$. All revisions included implant revisions, iliac crest bone grafting, and rhBMP-2 use. One patient required irrigation and debridement of an rhBMP-induced seroma. Another patient required return to the operating room to repair a dural tear. There were no neurological, infectious, airway, or implant-related complications. Revision utilizing rhBMP-2 achieved fusion in $100 \%(n=8)$ of patients. The average length of follow-up was 42.6 months. All patients demonstrated solid fusion mass on the last radiograph.

CONCLUSIONS This is the first case series reporting the successful use of rhBMP-2 to facilitate cervical spine fusion in patients with DS after previous nonunion. In addition, few rhBMP-2-related postoperative complications occurred.

https://thejns.org/doi/abs/10.3171/2019.11.PEDS19622

KEYWORDS cervical spine; spine fusion; bone morphogenetic protein; Down syndrome

I NDIVIDUALS with Down syndrome (DS; trisomy 21) have ligamentous laxity and are prone to cervical instability, as well as other orthopedic issues. ${ }^{22}$ Atlantoaxial instability (AAI) is estimated to occur in $12 \%$ to $30 \%$ of individuals with DS but is only symptomatic in up to $1.5 \% .4,5,10,21,27,28,32$ Despite its low prevalence, symptomatic AAI can be life-threatening. Atlantoaxial subluxation can result in dynamic cervical stenosis causing pain and neurological symptoms, including gait abnormalities, hy- perreflexia, spasticity, clonus, and loss of bowel and bladder control. ${ }^{7,22,26}$

Children with DS who have AAI with neurological findings, myelomalacia, pain, or rotary subluxation may require cervical spine fusion, which often results in nonunion requiring repeat operations (B. W. Yang et al., unpublished data). ${ }^{6,11,17,19,22,23,31}$ Brockmeyer et al. reviewed a large pediatric case series and concluded that DS is a risk factor for atlantoaxial pseudarthrosis. ${ }^{6}$

ABBREVIATIONS AAI = atlantoaxial instability; DS = Down syndrome; rhBMP-2 = recombinant human bone morphogenetic protein-2.

SUBMITTED October 18, 2019. ACCEPTED November 25, 2019.

INCLUDE WHEN CITING Published online January 31, 2020; DOI: 10.3171/2019.11.PEDS19622. 
Recombinant human bone morphogenetic protein-2 (rhBMP-2) is a TGF- $\beta$ growth factor critical for cartilage development and significant in bone development. ${ }^{8} \mathrm{Re}-$ combinant human BMP-2 is increasingly used in spine fusion to induce bone formation. ${ }^{8,29}$ It is approved by the FDA for certain orthopedic trauma and lumbar spine fusion indications. The complication rate with rhBMP-2 in spine fusion has been reported at $0.66 \%$ to $21.8 \%$. ${ }^{34}$ Recent literature has focused on the complications of rhBMP-2 seen with long-term follow-up. ${ }^{3,18,35} \mathrm{In}$ addition, several studies have compared spine fusions with and without rhBMP-2 and found no significant difference in pseudarthrosis rates. ${ }^{13,14,29}$ However, the majority of this research focuses on subaxial fusion in adult patients without DS. Pediatric literature on the efficacy of rhBMP-2 is limited and has not focused specifically on patients with DS. ${ }^{30} \mathrm{Si}-$ emionow et al. described 17 adults with DS who underwent cervical spine fusion with rhBMP-2. Three required revision due to nonunion. ${ }^{33}$ Three case reports have demonstrated complete cervical fusion using rhBMP-2 in children with a medical complexity including DS..$^{20,24,25}$

Given the lack of literature on this topic, we report the first series of pediatric patients with DS who underwent successful revision with the use of rhBMP-2, autograft iliac crest bone grafting, and revision instrumentation for failed initial upper cervical fusion for instability.

\section{Methods}

We reviewed a database of 175 patients who underwent cervical spine fusions using modern instrumentation at our tertiary care pediatric hospital from 2002 to 2019. Our institutional review board approved the database and this study. This study included patients with DS who underwent revision surgery at Boston Children's Hospital for failed previous upper cervical spine surgery due to pseudarthrosis.

After patient identification, medical records were reviewed to determine the number of prior fusions, rhBMP-2 use in initial and revision procedures, length of stay, and halo use for all patients. Curated intraoperative variables included surgical approach, levels fused, instrumentation, graft type, and complications. Postoperative complications, revision procedures, and length of follow-up were also recorded.

Nonunion in the preoperative state was determined by implant loosening or failure or a CT scan showing clear nonunion. All patients with radiographic suggestion of pseudarthrosis underwent revision, even if they were asymptomatic. Our experience is that over time, if left alone, implant loosening will progress and revision surgery will be more difficult. Presence of fusion was determined by appearance of fusion mass, lack of motion on flexion or extension radiographs, stable implants, and, in some patients, findings on a CT scan.

\section{Results}

Eight patients met inclusion criteria. Seventy-five percent (6/8) of the cohort was female. The average age at revision with rhBMP-2 was 11 years (range 3-19 years). Two patients had os odontoideum with AAI. Multiple pa-
TABLE 1. Patients experiencing intra- and postoperative complications

\begin{tabular}{ccc}
\hline & $\begin{array}{c}\text { Intraop } \\
\text { Pt }\end{array}$ & Complication \\
\hline A & & $\begin{array}{c}\text { Increased wound drainage; dural tear \& CSF leak } \\
\text { requiring repair, drain placement }\end{array}$ \\
\hline B & & $\begin{array}{c}\text { Increased wound drainage; hematoma \& seroma } \\
\text { requiring I\&D, drain placement }\end{array}$ \\
\hline H & $\begin{array}{c}\text { Durotomy } \\
\text { (repaired) }\end{array}$ & $\begin{array}{r}\text { Recurrent pneumonia } \\
\end{array}$ \\
\hline
\end{tabular}

$\mathrm{I} \mathrm{D}=$ irrigation and debridement; $\mathrm{Pt}=$ patient.

tients had additional complications of DS, including heart defects, thyroid conditions, ear diseases, and low bone density.

All patients previously underwent cervical spine instrumentation that resulted in nonunion. One patient had 2 prior attempts at fusion, and 7 patients had 1 prior attempt at fusion. The average time from the previous operation to revision surgery with rhBMP-2 was 16 months (range 4-36 months). Only one patient had an original procedure in which rhBMP-2 was used.

The majority (7/8) of patients used halo traction at some point during their care. Most (5/8) patients had a halo attached intraoperatively before surgical fixation and remained in a halo vest postoperatively. One patient had halo traction preoperatively for reduction of basilar invagination and continued in a halo vest postoperatively, and another had halo-crown traction solely intraoperatively. Among the 6 patients who used halos beyond the intraoperative period, the average length of halo vest traction was 100 days (range $73-147$ days).

An orthopedic surgeon and neurosurgeon were present at all procedures. All revisions were done using a posterior approach and involved the fusion of $\mathrm{C} 1$ and $\mathrm{C} 2$. Six procedures involved occiput to cervical fusion. Levels fused ranged from 1 to 5 , with the longest fusion from the occiput to C5. All revisions involved iliac crest autograft; allograft was also used in 7 patients. All patients underwent revision instrumentation with rigid screw-plate-rod constructs. Intraoperative complications were limited to 1 case of durotomy, which was recognized and repaired intraoperatively without any clinical sequela.

The average length of stay was 13 days (range 3-44 days), but the majority (5/8) of patients stayed for 8 days or less. The patients who stayed longer (3/8) either were hospitalized preoperatively for halo placement and gradual traction $(1 / 8)$ or had postoperative complications $(2 / 8)$. The patient treated with preoperative halo traction had significant basilar invagination and myelopathy and was hospitalized for traction to gradually reduce the invagination. This resulted in a 44-day length of stay. Calculating hospitalization from date of surgery to discharge reveals a more accurate average length of stay of 8.5 days (range 3-16 days).

All patients had drains placed. Increased wound drainage, a common sequela of rhBMP-2, was noted in 2 patients postoperatively. Two patients required a return to the 



FIG. 1. Radiographs demonstrating fusion mass and stability on flexion (left) and extension (right) at the 7-month follow-up.

operating room due to drainage from the surgical wound in the immediate postoperative period. One of these patients had a sterile rhBMP-induced seroma. The other patient was suspected to have an rhBMP-induced seroma, but at the time of exploration was found to have a cerebrospinal fluid collection; a dural tear was found and repaired between $\mathrm{C} 1$ and $\mathrm{C} 2$. There were no additional sequelae in either patient.

The revision procedure with rhBMP-2 successfully achieved fusion in all 8 patients. No patients required surgical revision aside from the noted procedures related to postoperative complications (Table 1). The average length of follow-up was 42.6 months (range 7-113 months). Two patients had less than 2 years of follow-up. One out-of-state patient did not undergo follow-up beyond 7 months because they were asymptomatic and exhibited radiographic fusion at their last appointment (Fig. 1). The patient with the most recent procedure also had a shorter follow-up of 7 months to date (Fig. 2). Both of these patients demonstrated a solid fusion mass on the last radiograph, compensating for their shorter follow-up, and are in regular communication with our team if out of state (Figs. 1 and 2).

\section{Discussion}

This case series demonstrates the potential effectiveness of rhBMP-2, alongside other factors, in achieving cervical spine fusion in children with DS undergoing revision for nonunion. Previous research and our surgeons' experiences have emphasized the difficulty in obtaining fusion in this population and the frequent need for multiple revisions (B. W. Yang et al., unpublished data). ${ }^{6,11,17,19,22,23,31}$ With recent studies focusing on potential side effects of rhBMP-2 in otherwise healthy adults, it is important to note that our cohort experienced limited rhBMP-2-related complications, and fusion was achieved in all patients.

Our findings are in accordance with a small but growing body of literature that has reported that rhBMP-2 leads to better, quicker fusion in pediatric orthopedic trauma. ${ }^{1,12,15,16}$ Specific to cervical spine fusion, case reports have demonstrated success with rhBMP-2 in children with
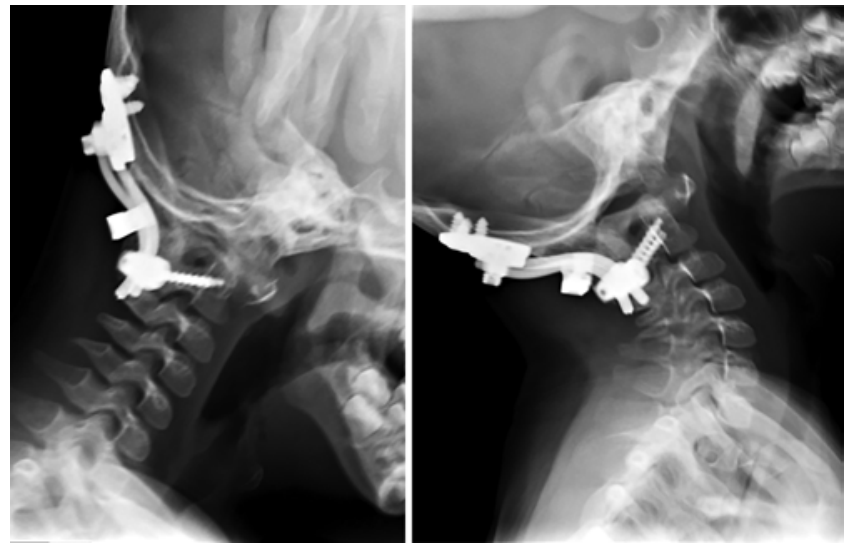

FIG. 2. Radiographs demonstrating fusion mass and stability on flexion (left) and extension (right) at the 7-month follow-up.

DS as young as 4 months and in a medically complex child with Hurler's syndrome. ${ }^{20,24,25}$ Our larger cohort, in addition to previous research, raises suspicion that rhBMP-2 may be more beneficial in children than adults.

One patient in our database with DS and AAI had reoperations using rhBMP-2 after initial surgery, but neither procedure involved instrumentation revision. For this reason, this patient was excluded from the cohort. There was delayed union after the initial operation, and the patient underwent 2 bone grafts and rhBMP-2 with implant revision, which resulted in fusion. This specific case further demonstrates the effectiveness of rhBMP-2 and its potential to salvage fusion without instrumentation revision when delayed union is expected.

We observed a female majority in our cohort $(75 \%$, $6 / 8$ ). Some research has suggested that AAI is more frequent and severe in females with DS, but this topic has not been researched recently. ${ }^{2,9}$ It would be useful to focus on patient characteristics like this in the future as we learn more about this patient population and how to treat them.

We also acknowledge that the revision procedures involved instrumentation to a more rigid construct, iliac crest bone grafting, and, in a majority of patients, prolonged use of a halo vest. The argument can be made that rhBMP-2 is one of many factors responsible for fusion in these patients and that no conclusions may be definitively made. We also believe that this series represents an incredibly difficult operative series and that reporting positive rhBMP-2 use may aid other surgeons who encounter this challenging patient population.

Potential limitations include surgeon variability, patient complexity, and missing information due to retrospective review. For the purpose of this study, it was more important to include as many eligible patients as possible given the rarity of this population and procedure. While not all patients have standard 2-year follow-up, those patients who do not fit into that time period have clear radiological evidence of fusion based on continuous fusion mass and no evidence of implant failure or recurrent deformity.

\section{Conclusions}

This case series represents the only group of children 
reported on who underwent successful fusion for a failed previous arthrodesis attempt for upper cervical instability associated with DS. This is the largest single series of children with DS who underwent fusion with rhBMP-2 from one institution. It is difficult to compare this study with existing research because of the limited nature of pediatric case reports and dissimilarity with larger adult studies, which mostly focus on subaxial fusion in patients without DS.

Future research should focus on multicenter studies to analyze a larger cohort of children with DS undergoing revision with rhBMP-2. The majority of existing pediatric research disagrees with findings in adults. However, the efficacy of rhBMP-2 in pediatric cervical spine fusion cannot be validated until studies comparable to those in adults are conducted. Based on the experience detailed in this series, we recommend the use of rhBMP-2 during the initial procedure in children with DS.

\section{References}

1. Alt V, Borgman B, Eicher A, Heiss C, Kanakaris NK, Giannoudis PV, et al: Effects of recombinant human bone morphogenetic protein-2 (rhBMP-2) in grade III open tibia fractures treated with unreamed nails - a clinical and healtheconomic analysis. Injury 46:2267-2272, 2015

2. Alvarez N, Rubin L: Atlantoaxial instability in adults with Down syndrome: a clinical and radiological survey. Appl Res Ment Retard 7:67-78, 1986

3. Barcak EA, Beebe MJ: Bone morphogenetic protein: is there still a role in orthopedic trauma in 2017? Orthop Clin North Am 48:301-309, 2017

4. Bertolizio G, Saint-Martin C, Ingelmo P: Cervical instability in patients with trisomy 21: the eternal gamble. Paediatr Anaesth 28:830-833, 2018

5. Brockmeyer D: Down syndrome and craniovertebral instability. Topic review and treatment recommendations. Pediatr Neurosurg 31:71-77, 1999

6. Brockmeyer DL, Sivakumar W, Mazur MD, Sayama CM, Goldstein HE, Lew SM, et al: Identifying factors predictive of atlantoaxial fusion failure in pediatric patients: lessons learned from a retrospective pediatric craniocervical society study. Spine (Phila Pa 1976) 43:754-760, 2018

7. Bull MJ: Health supervision for children with Down syndrome. Pediatrics 128:393-406, 2011

8. Chen D, Zhao M, Mundy GR: Bone morphogenetic proteins. Growth Factors 22:233-241, 2004

9. Davidson RG: Atlantoaxial instability in individuals with Down syndrome: a fresh look at the evidence. Pediatrics 81:857-865, 1988

10. Dedlow ER, Siddiqi S, Fillipps DJ, Kelly MN, Nackashi JA, Tuli SY: Symptomatic atlantoaxial instability in an adolescent with trisomy 21 (Down's syndrome). Clin Pediatr (Phila) 52:633-638, 2013

11. Doyle JS, Lauerman WC, Wood KB, Krause DR: Complications and long-term outcome of upper cervical spine arthrodesis in patients with Down syndrome. Spine (Phila Pa 1976) 21:1223-1231, 1996

12. Govender S, Csimma C, Genant HK, Valentin-Opran A, Amit Y, Arbel R, et al: Recombinant human bone morphogenetic protein-2 for treatment of open tibial fractures: a prospective, controlled, randomized study of four hundred and fifty patients. J Bone Joint Surg Am 84:2123-2134, 2002

13. Guppy KH, Harris J, Chen J, Paxton EW, Alvarez J, Bernbeck J: Reoperation rates for symptomatic nonunions in posterior cervical (subaxial) fusions with and without bone morphogenetic protein in a cohort of 1158 patients. J Neurosurg Spine 24:556-564, 2016

14. Guppy KH, Paxton EW, Harris J, Alvarez J, Bernbeck J: Does bone morphogenetic protein change the operative nonunion rates in spine fusions? Spine (Phila Pa 1976) 39:18311839,2014

15. Herford AS: The use of recombinant human bone morphogenetic protein-2 (rhBMP-2) in maxillofacial trauma. Chin J Traumatol 20:1-3, 2017

16. Hissnauer TN, Stiel N, Babin K, Rupprecht M, Ridderbusch $\mathrm{K}$, Rueger JM, et al: Recombinant human bone morphogenetic protein-2 (rhBMP-2) for the treatment of nonunion of the femur in children and adolescents: a retrospective analysis. BioMed Res Int 2017:3046842, 2017

17. Hofler RC, Pecoraro N, Jones GA: Outcomes of surgical correction of atlantoaxial instability in patients with Down syndrome: systematic review and meta-analysis. World Neurosurg 126:e125-e135, 2019

18. Jain A, Hassanzadeh H, Strike SA, Skolasky RL, Riley LH III: rhBMP use in cervical spine surgery: associated factors and in-hospital complications. J Bone Joint Surg Am 96:617-623, 2014

19. Lerman JA, Emans JB, Hall JE, Karlin LI: Spinal arthrodesis for scoliosis in Down syndrome. J Pediatr Orthop 23:159-161, 2003

20. Lu DC, Sun PP: Bone morphogenetic protein for salvage fusion in an infant with Down syndrome and craniovertebral instability. Case report. J Neurosurg 106 (6 Suppl):480-483, 2007

21. Matsuda Y, Sano N, Watanabe S, Oki S, Shibata T: Atlantooccipital hypermobility in subjects with Down's syndrome. Spine (Phila Pa 1976) 20:2283-2286, 1995

22. McKay SD, Al-Omari A, Tomlinson LA, Dormans JP: Review of cervical spine anomalies in genetic syndromes. Spine (Phila Pa 1976) 37:E269-E277, 2012

23. Milbrandt TA, Johnston CE 2nd: Down syndrome and scoliosis: a review of a 50-year experience at one institution. Spine (Phila Pa 1976) 30:2051-2055, 2005

24. Mladenov KV, Kunkel P, Stuecker R: The use of recombinant human BMP-2 as a salvage procedure in the pediatric spine: a report on 3 cases. Eur Spine J 19 (Suppl 2):S135-S139, 2010

25. Molinari RW, Molinari C: The use of bone morphogenetic protein in pediatric cervical spine fusion surgery: case reports and review of the literature. Global Spine J 6:e41-e46, 2016

26. Pueschel SM: Atlanto-axial subluxation in Down syndrome. Lancet 1:980, 1983 (Letter)

27. Pueschel SM: Should children with Down syndrome be screened for atlantoaxial instability? Arch Pediatr Adolesc Med 152:123-125, 1998

28. Pueschel SM, Scola FH: Atlantoaxial instability in individuals with Down syndrome: epidemiologic, radiographic, and clinical studies. Pediatrics 80:555-560, 1987

29. Rocque BG, Kelly MP, Miller JH, Li Y, Anderson PA: Bone morphogenetic protein-associated complications in pediatric spinal fusion in the early postoperative period: an analysis of 4658 patients and review of the literature. J Neurosurg Pediatr 14:635-643, 2014

30. Sayama C, Hadley C, Monaco GN, Sen A, Brayton A, Briceño V, et al: The efficacy of routine use of recombinant human bone morphogenetic protein-2 in occipitocervical and atlantoaxial fusions of the pediatric spine: a minimum of 12 months' follow-up with computed tomography. J Neurosurg Pediatr 16:14-20, 2015

31. Segal LS, Drummond DS, Zanotti RM, Ecker ML, Mubarak SJ: Complications of posterior arthrodesis of the cervical spine in patients who have Down syndrome. J Bone Joint Surg Am 73:1547-1554, 1991 
32. Semine AA, Ertel AN, Goldberg MJ, Bull MJ: Cervicalspine instability in children with Down syndrome (trisomy 21). J Bone Joint Surg Am 60:649-652, 1978

33. Siemionow K, Hansdorfer M, Janusz P, Mardjetko S: Complications in adult patients with Down syndrome undergoing cervical spine surgery using current instrumentation techniques and rhBMP-2: a long-term follow-up. J Neurol Surg A Cent Eur Neurosurg 78:113-123, 2017

34. Singh K, Ahmadinia K, Park DK, Nandyala SV, MarquezLara A, Patel AA, et al: Complications of spinal fusion with utilization of bone morphogenetic protein: a systematic review of the literature. Spine (Phila Pa 1976) 39:91-101, 2014

35. Tannoury CA, An HS: Complications with the use of bone morphogenetic protein 2 (BMP-2) in spine surgery. Spine $\mathbf{J}$ 14:552-559, 2014

\section{Disclosures}

The authors report no conflict of interest concerning the materials or methods used in this study or the findings specified in this paper.

\section{Author Contributions}

Conception and design: Hedequist. Acquisition of data: all authors. Analysis and interpretation of data: all authors. Drafting the article: Hedequist, Cohen, O’Neill. Critically revising the article: all authors. Reviewed submitted version of manuscript: all authors. Approved the final version of the manuscript on behalf of all authors: Hedequist. Statistical analysis: Cohen. Administrative/technical/material support: Hedequist. Study supervision: Hedequist.

\section{Supplemental Information}

Current Affiliations

Dr. Yang: Department of Orthopaedic Surgery, Hospital for Special Surgery, New York, NY.

\section{Correspondence}

Daniel J. Hedequist: Boston Children's Hospital, Boston, MA. daniel.hedequist@childrens.harvard.edu. 